\title{
Blown sand motion within the sand-control system in the southern section of the Taklimakan Desert Highway
}

\author{
CHENG Hong ${ }^{1,2}$, HE Jiajia ${ }^{1,2^{*}}$, XU Xingri ${ }^{1,2,3}$, ZOU Xueyong ${ }^{1,2}$, WU Yongqiu ${ }^{1,2}$, LIU Chenchen ${ }^{1,2}$, \\ DONG Yifan ${ }^{1,2}$, PAN Meihui ${ }^{1,2}$, WANG Yanzai ${ }^{1,2}$, ZHANG Hongyan ${ }^{1,2}$ \\ ${ }^{1}$ State Key Laboratory of Earth Surface Processes and Resource Ecology, Beijing Normal University, Beijing 100875, China; \\ ${ }^{2}$ MOE Engineering Center of Desertification and Blown-sand Control at Beijing Normal University, Beijing 100875, China; \\ ${ }^{3}$ Lushunkou Trading Center of Land Reserve, Dalian 116041, China
}

\begin{abstract}
Although scientists have performed many studies in the Taklimakan Desert, few of them have reported the blown sand motion along the southern edge of the Taklimakan Desert Highway, which differs significantly from the northern region in terms of aeolian sand geomorphology and formation environment. Based on the field observation data of airflow and aeolian sand transport, continuous monitoring data of erosional and depositional processes between 14 April 2009 and 9 April 2011 and data of surface sand grains from the classical section along the southern edge of the Taklimakan Desert Highway, this paper reported the blown sand motion within the sand-control system of the highway. The main results are as follows: 1) The existing sand-control system is highly effective in preventing and controlling desertification. Wind velocities within the sand-control system were approximately $33 \%-100 \%$ of those for the same height above the mobile sand surface. Aeolian sand fluxes were approximately $0-31.21 \%$ of those of the mobile sand surface. Sand grains inside the system, with a mean diameter of $2.89 \varphi$, were finer than those $(2.15 \varphi)$ outside the system. In addition, wind velocities basically followed a logarithmic law, but the airflow along the classical section was mainly determined by topography and vegetation. 2) There were obvious erosional and depositional phenomena above the surface within the sand-control system, and these phenomena have very consistent patterns for all observation points in the two observed years. The total thicknesses of erosion and deposition ranged from 0.30 to $14.60 \mathrm{~cm}$, with a mean value of $3.67 \mathrm{~cm}$. In contrast, the deposition thicknesses were $1.90-22.10 \mathrm{~cm}$, with a mean value of $7.59 \mathrm{~cm}$, and the erosion thicknesses were $3.51-15.10 \mathrm{~cm}$, with a mean value of $8.75 \mathrm{~cm}$. The results will aid our understanding of blown sand within the sand-control system and provide a strong foundation for optimizing the sand-control system.
\end{abstract}

Keywords: sand-control system; blown sand motion; erosion; deposition; Taklimakan Desert Highway

Citation: CHENG Hong, HE Jiajia, XU Xingri, ZOU Xueyong, WU Yongqiu, LIU Chenchen, DONG Yifan, PAN Meihui, WANG Yanzai, ZHANG Hongyan. 2015. Blown sand motion within the sand-control system in the southern section of the Taklimakan Desert Highway. Journal of Arid Land, 7(5): 599-611. doi: 10.1007/s40333-015-0126-9

The Taklimakan Desert is the second largest mobile desert in the world, with approximately $85 \%$ of its area being covered with mobile sand dunes (Lei et al., 2008a, b). Scientists have studied the environmental evolution ( $\mathrm{Li}$ et al., 1990), the formation (Wu, 1981; Zhu et al., 1981), particle characteristics (Chen, 1993; He et al., 2012) of sand grains, and blown sand movement in this desert (Lin, 1988; Han et al., 2003). Researchers have also classified the geomorphology of the aeolian sand region and studied its shape, for- mation and development of the geomorphology (Wang et al., 2002a, b). These studies have helped to improve the understanding of the formation and evolution of the Taklimakan Desert. The total length of the Taklimakan Desert Highway is $562 \mathrm{~km}, 446 \mathrm{~km}$ of which is within the mobile-sand region (Lei et al., 2008a). The blown sand environment presents formidable challenges along the highway. Therefore, effective measures to prevent and control desertification are essential.

"Corresponding author: HE Jiajia (E-mail: 201231480004@mail.bnu.edu.cn)

Received 2014-08-07; revised 2014-12-10; accepted 2015-02-06

(c) Xinjiang Institute of Ecology and Geography, Chinese Academy of Sciences, Science Press and Springer-Verlag Berlin Heidelberg 2015 
Before the highway was established, a 2-km pilot experimental road section in Mancan was built in 1991 (Fig. 1). To prevent and control desertification, the minimum belt widths of straw checkerboards on the upwind and leeward sides of the highway were 45-70 and 30-50 m, respectively (Jin et al., 2007). Since the construction of the highway, scientists have long been focusing on the environmental characteristics of the desert (Xia et al., 1995), the migration of sand dunes (Zhang et al., 1999), the formation and intensities of blown sand hazards (Dong et al., 1997; Lei et al., 2002, 2008b; Li, et al., 2006; Jin et al., 2008), the temporal and spatial variations of blown sand activities (Lei et al., 2002; Han et al., 2005), and the establishment and efficiency of desertification prevention and control systems based on a straw checkerboard pattern (Han et al., 1993; Jin et al., 2005; $\mathrm{Qu}$ et al., 2005). These studies contributed to the control of blown sand hazards along the Taklimakan Desert Highway.

These previous studies fully focused on the northern region of Tazhong, a section approximately $220 \mathrm{~km}$ long in the mobile-sand region (Fig. 1). The southern $220-\mathrm{km}$ section presents obvious differences in ae- olian sand geomorphology and environment, but blown sand motion has seldom been reported in the literature. Furthermore, few studies have reported the blown sand motion along the Taklimakan Desert Highway since a shelterbelt was established in 2005 . Researchers have identified geomorphology changes due to the effects of the Taklimakan Desert Highway shelterbelt, variations in wind velocities and aeolian flux (Lei et al., 2008a). The wind velocity at $1 \mathrm{~m}$ height within the shelterbelt was approximately $22.73 \%-50.00 \%$ that of the mobile sand located outside of the shelterbelt, and the aeolian flux $0-20 \mathrm{~cm}$ within the shelterbelt was approximately $0.98 \%$ $12.55 \%$ that of the mobile sand located outside of shelterbelt (Lei et al., 2008a). In addition, the high cost of construction and maintenance of the shelterbelt forced scientists to study how to optimize the shelterbelt; certain researchers even questioned the feasibility of such ecological engineering (Han et al., 2000; Jin et al., 2007). This paper investigated blown sand motion within the sand-control system at the southern edge of the Taklimakan Desert Highway using field observation data. The results will aid our understanding of the formation and evolution processes of aeolian sand

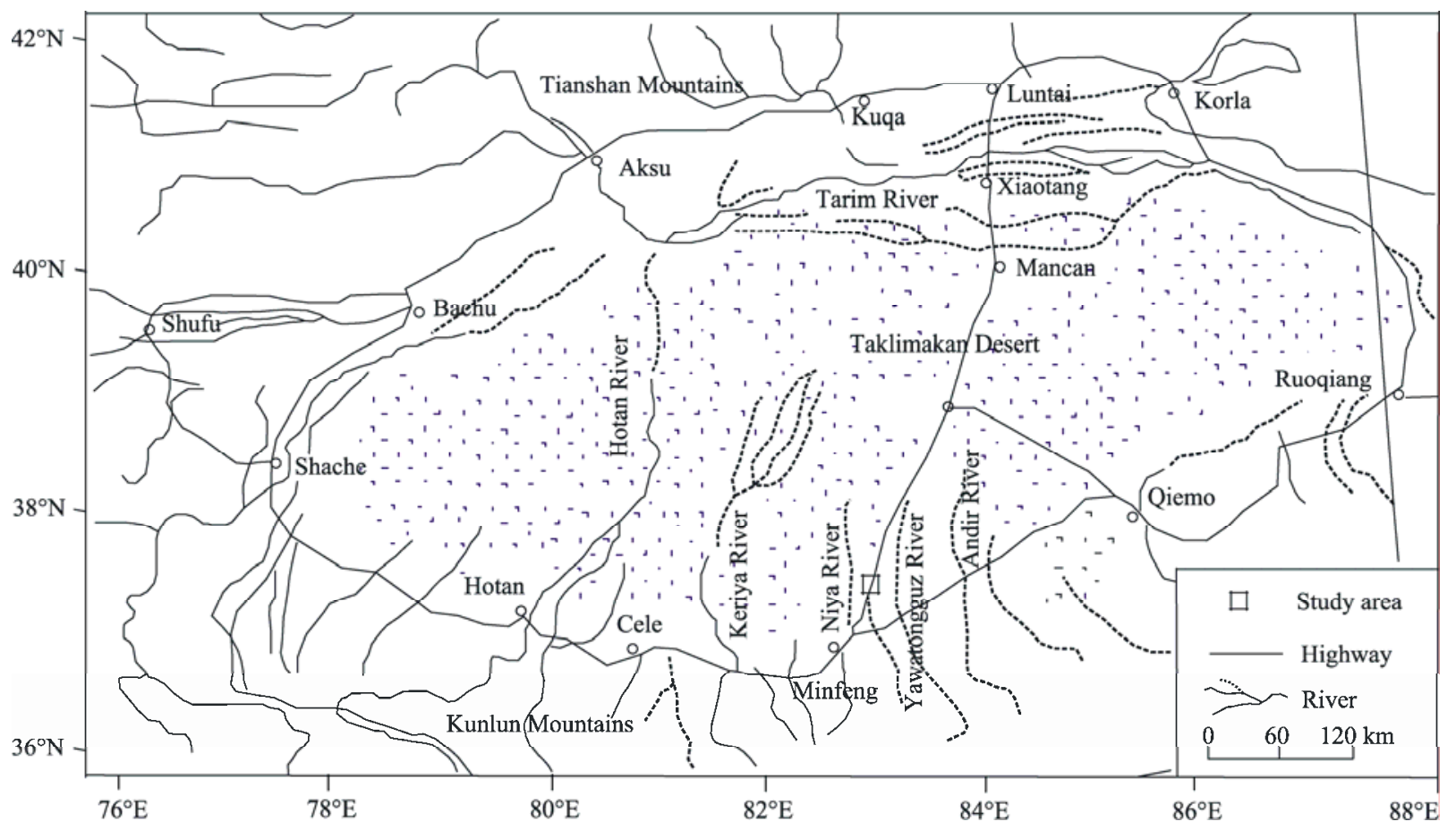

Fig. 1 Location of the study area 
geomorphology in the southern region of the Taklimakan Desert.

\section{Study area}

The study area is located in the southern section of the Taklimakan Desert Highway, approximately $70 \mathrm{~km}$ from the city of Minfeng, Xinjiang Uygur autonomous region $\left(37.43011^{\circ} \mathrm{N}, 82.84851^{\circ} \mathrm{E}\right.$; Fig. 1$)$. The elevation ranges from $1,075.15$ to $1,082.72 \mathrm{~m}$. The annual average temperature is approximately $11.5^{\circ} \mathrm{C}$. The average annual precipitation is $38.3 \mathrm{~mm}$, and the average annual evaporation is $2,862 \mathrm{~mm}$. Therefore, the region has a warm-temperate and extremely arid climate (Liu, 2009).

According to statistics from the Minfeng meteorological station for the period of 1957-2009, there are two opposing prevailing wind directions, NE and WSW-W-SW (Fig. 2), which accounted for $80.32 \%$ of all recorded wind directions. Moreover, the NE component accounted for approximately $13.77 \%$, and the WSW, W and SW components represented approximately $32.19 \%, 23.38 \%$ and $10.98 \%$, respectively. These were not consistent with previous studies, which found four prevailing wind directions (ENE, E, $\mathrm{NE}$ and NNE) in the northern region of Tazhong (Lei et al., 2002). The differences between the northern and southern Taklimakan Desert are likely due to the

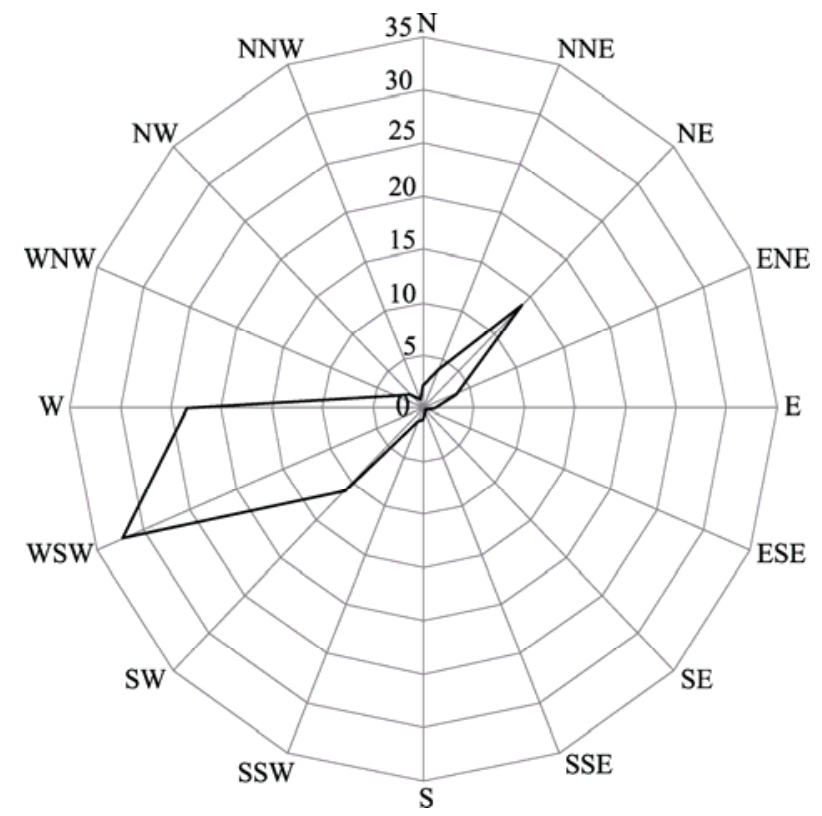

Fig. 2 A rose diagram of wind directions at the Minfeng meteorological station between 1957 and 2009 differences in wind direction. In fact, it was necessary to study the changes in wind direction in different areas of the Taklimakan Desert. In addition, wind with velocities greater than $5 \mathrm{~m} / \mathrm{s}$ occurs most frequently in April-July (Fig. 3).

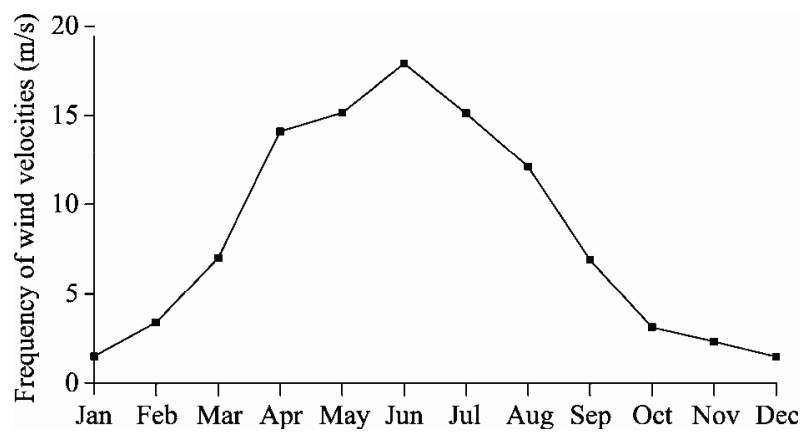

Fig. 3 Frequency of wind velocities greater than $5 \mathrm{~m} / \mathrm{s}$ for the months of 1957-2009 at the Minfeng meteorological station

\section{Methods}

\subsection{Topographic measurements}

A topographic survey was made using a GPS system (Trimble 5800 RTK) with planimetric and altimetric precision values of $1 \mathrm{~cm} \pm 1 \mu \mathrm{m}$ and $2 \mathrm{~cm} \pm 2 \mu \mathrm{m}$, respectively. First, we measured the boundary of the 150-m sand-control system, including reed fences, straw checkerboards and protective forest belts. Second, detailed measurements were made in each sand-control system. The mean distance between two points was approximately $2-3 \mathrm{~m}$. However, for certain areas with large landform variations, more intensive measurements were taken, and the distance between two points was approximately $0.5 \mathrm{~m}$ or less. The geographic coordinates and their attributes were recorded in a GPS. A total of 3,468 points were measured across the $0.024-\mathrm{km}^{2}$ study area.

\subsection{Survey of the prevention and control system}

The prevention and control system was surveyed in April 2009. Based on the GPS points and their attributes, a contour map of the study area was drawn with black lines, and a layout map of the sand-control system along the Minfeng section of the Taklimakan Desert Highway was drawn with dotted lines (Fig. 4). The layout of the sand-control system included the eastern and western sides of the highway. On the 


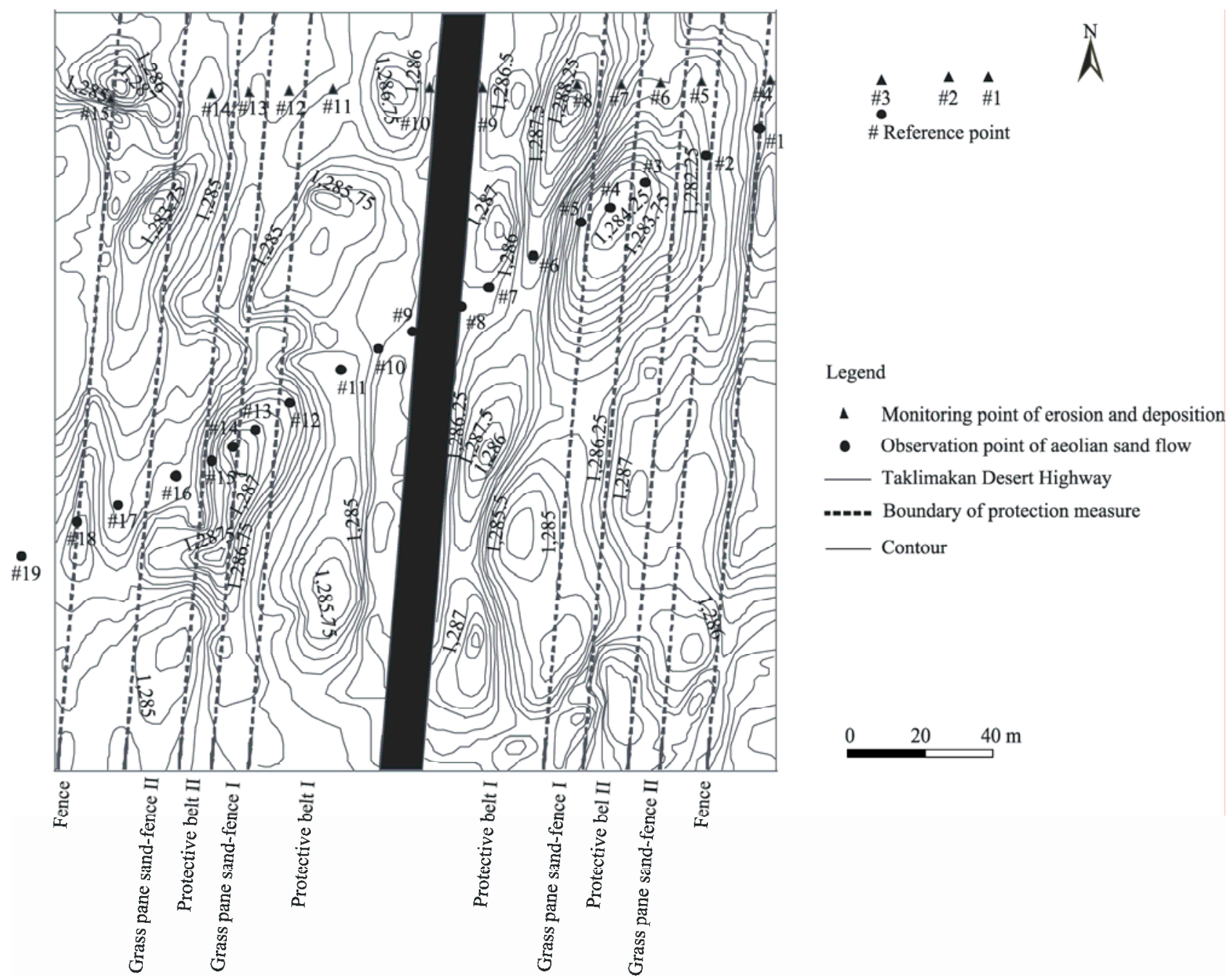

Fig. 4 The layout of the classical section for the sand-control system in the southern section of the Taklimakan Desert Highway

eastern side, the system consists of a fence (I), a set of straw checkerboards (II) with 5 lines and a $1-\mathrm{m}$ percent line, a protective belt (II) with 5 lines and a 2-m percent line, a set of straw checkerboards (I) with 5 lines, and a protective belt (I) with 12 lines. On the western side, the sand-control system consists of a protective belt (I) with 14 lines, a set of straw checkerboards (I) with 6 lines, a protective belt (II) with 5 lines, a set of straw checkerboards (II) with 10 lines and a fence (I). The fences and straw checkerboards are composed of reed straws, and the tree species in the protective belt are Haloxylon ammodendron and Calligonum arborescens Litv. Thus, the sand-control system focuses on sand binding and assists with sand trapping.

The fences were mostly covered with mobile sand.
The mean height of fences above the sand surface was $10.75 \mathrm{~cm}$. The majority of the straw checkerboards were also mostly buried by mobile sand. Trees in the upwind protective belt II were of the species C. arborescens and those in the upwind protective belt I and in the leeward protective belts I and II were of the species C. arborescens and $H$. ammodendron. As a whole, the growth of H. ammodendron was better than that of C. arborescens. For example, the mean heights of $C$. arborescens and $H$. ammodendron were 90 and $140 \mathrm{~cm}$, respectively; and the mean crown dimensions (width vertical to highway and width parallel to highway) of the two species were $99 \mathrm{~cm} \times 140 \mathrm{~cm}$ and $140 \mathrm{~cm} \times 165 \mathrm{~cm}$, respectively. 


\subsection{Measurement of blown sand flow}

In total, 20 points $(\# 1, \# 2, \ldots, \# 19$, and a reference point) were used to observe blown sand flow (Fig. 4). The reference point was located at the crest of a sand dune outside the sand-control system, and the other 19 points were within the sand-control system. During the observation of blown sand flow, an automatic multipoint anemometer and a sampler were located at the reference point, and another anemometer and sampler set was located at \#1 (or \#2, etc.) (Fig. 5). The anemometers automatically recorded wind directions from $0^{\circ}$ to $360^{\circ}$ and measured the average wind speed every minute at nine different heights $(5,10,20,30$, $50,80,100,200$ and $300 \mathrm{~cm}$ ) with a resolution of $0.1 \mathrm{~m} / \mathrm{s}$ within a range of 0.3 to $30.0 \mathrm{~m} / \mathrm{s}$. The sampler, which could record 30 different height layers, captured aeolian sand flow from 0 to $60 \mathrm{~cm}$ above the surface. In this paper, the sampling time for blown sand was 10-15 minutes and was synchronized with the anemometer.

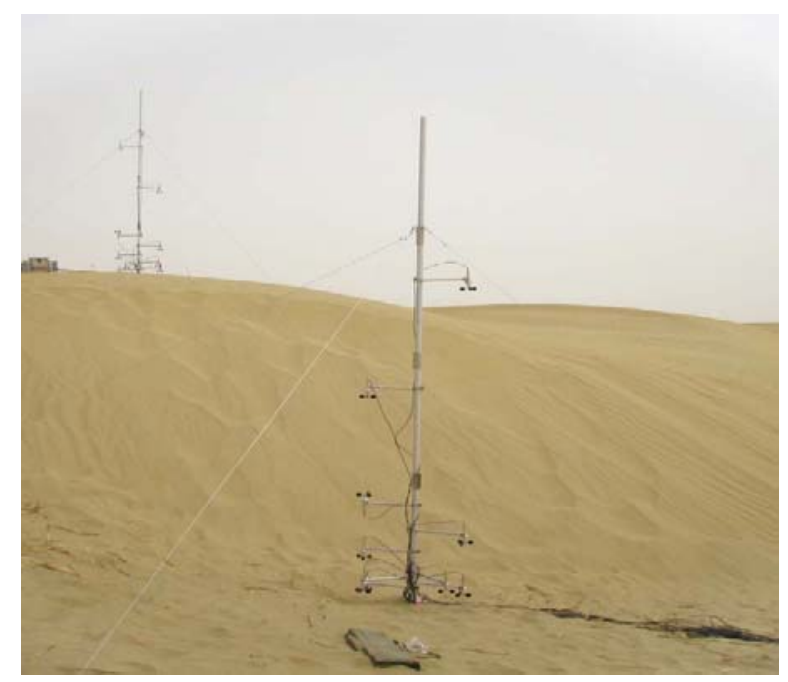

Fig. 5 Observation of aeolian sand flow

\subsection{Continuous monitoring of erosion and deposi- tion processes}

In total, 15 points $(\# 1, \# 2, \ldots, \# 15)$ were used to monitor erosional and depositional processes between 14 April 2009 and 9 April 2011 (Fig. 4). The line with 15 points was basically perpendicular to the highway. Except \#1, \#2, and \#3, the other 12 points were within the system. The points \#1, \#2 and \#3 were located at the toe of the windward slope, the middle part of a windward slope and the crest of a sand dune, respectively. In the absence of a dust storm, the heights of the erosion pins were measured every 10 days. The heights of the erosion pins were also measured at the end of a dust storm. The diameters of surface sand grain samples from the 15 monitoring points were measured using a Malven Mastersizer in the test center of Beijing Normal University.

\section{Results and discussion}

\subsection{Characteristics of airflow field within the sand-control system}

3.1.1 Wind velocity profiles for observation points

Figure 6 shows the average wind speed of different observation points at different heights. Although the sand-control system and topography significantly influence the airflow, the wind velocity profiles within the sand-control system followed an approximately logarithmic relationship $(u=\mathrm{a}+\mathrm{b} \ln (z)$, where $u$ is wind velocity, $a$ and $b$ are the fitting coefficients, and $z$ is height) (Fig. 6; Table 1) (Bagnold, 1941). The slope rate for the wind velocity profiles in the range from 0 to $100 \mathrm{~cm}$ on the upwind side of the highway were larger than those on the leeward side, indicating that the engineering specifications have a larger influence on wind velocity on the upwind side of the highway than those on the leeward side.

Table 1 Regression parameters of the wind velocity profiles

\begin{tabular}{|c|c|c|c|c|c|c|c|}
\hline \multirow{2}{*}{$\begin{array}{l}\text { Observation } \\
\text { point }\end{array}$} & \multicolumn{3}{|c|}{$u=\mathrm{a}+\mathrm{b} \ln (\mathrm{z})$} & \multirow{2}{*}{$\begin{array}{c}\text { Observation } \\
\text { point }\end{array}$} & \multicolumn{3}{|c|}{$u=\mathrm{a}+\mathrm{b} \ln (\mathrm{z})$} \\
\hline & $\mathrm{a}$ & $\mathrm{b}$ & $R^{2}$ & & $\mathrm{a}$ & $\mathrm{b}$ & $R^{2}$ \\
\hline$\# 1$ & 0.11 & 1.10 & 0.94 & \#11 & -1.75 & 1.11 & 0.86 \\
\hline$\# 2$ & -0.01 & 1.11 & 0.98 & $\# 12$ & -0.67 & 1.09 & 0.94 \\
\hline$\# 3$ & 1.03 & 0.65 & 0.94 & $\# 13$ & 1.94 & 0.74 & 0.92 \\
\hline$\# 4$ & -3.95 & 1.30 & 0.78 & $\# 14$ & -2.73 & 1.29 & 0.85 \\
\hline$\# 5$ & -0.85 & 0.74 & 0.87 & $\# 15$ & -9.05 & 2.26 & 0.88 \\
\hline \#6 & -0.91 & 1.00 & 0.89 & $\# 16$ & 0.17 & 0.70 & 0.87 \\
\hline$\# 7$ & -1.47 & 1.30 & 0.89 & $\# 17$ & 0.90 & 0.54 & 0.93 \\
\hline$\# 8$ & -2.36 & 1.04 & 0.63 & $\# 18$ & 2.96 & 0.40 & 0.81 \\
\hline$\# 9$ & 1.05 & 0.63 & 0.88 & \#19 & 2.10 & 0.50 & 0.95 \\
\hline$\# 10$ & -0.62 & 1.10 & 0.91 & - & - & - & - \\
\hline
\end{tabular}

Note: $u$ is wind velocity, a and $b$ are the fitting coefficients, and $z$ is height.

3.1.2 Horizontal characteristics of the airflow field along the cross-section of the sand-control system

For studying the horizontal characteristics of the 

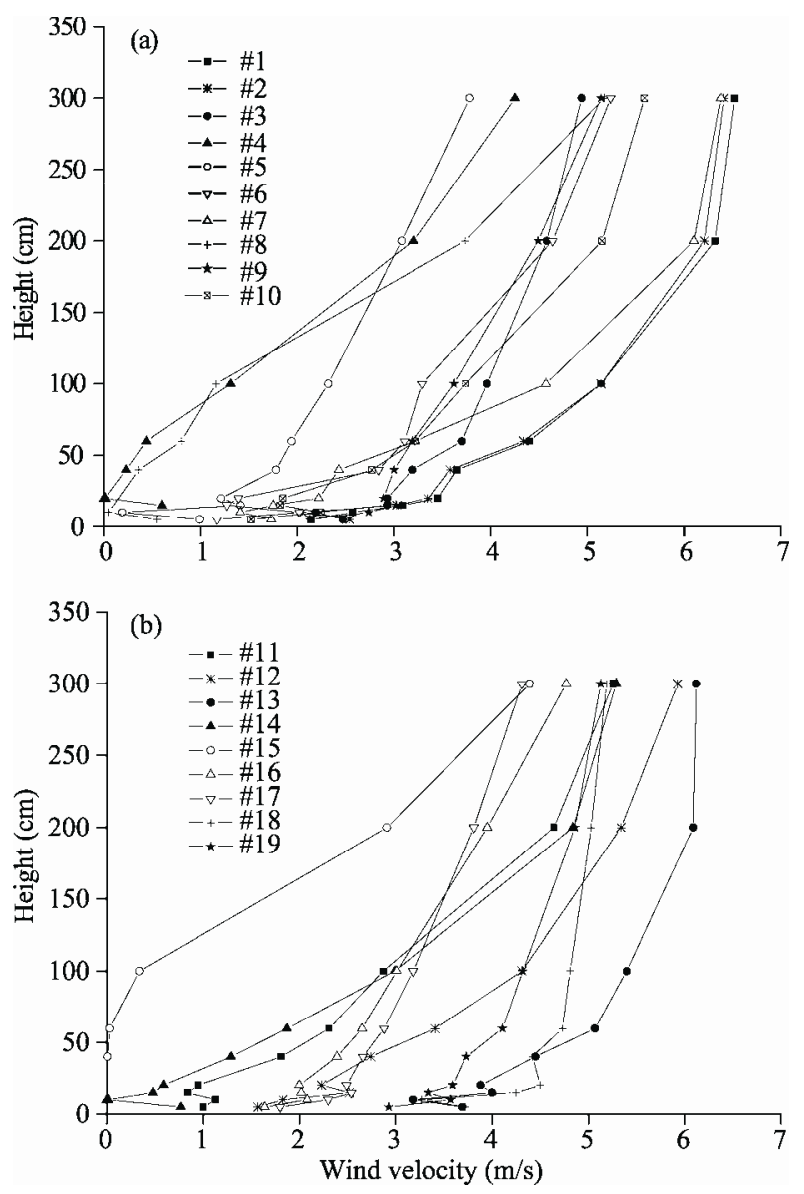

Fig. 6 The wind velocity profile of different observation points along the cross section of the sand-control system airflow field, the wind velocities of different observation points at different time must be converted into velocities at the same time:

$$
u_{z}=\frac{u_{\# 1}(t=10, z=10)}{u_{\# 1}(t, z=10)} \times u(t, z) .
$$

Where $u_{z}$ is the standardized wind velocity at height $z$ for a mobile point $(\# 2, \# 3, \ldots \# 18) ; u_{\# 1}(t=10, z=10)$ is the mean wind velocity at height $z$ for a reference point (\#1) within $(t, t+10)$ minutes; $u_{\# 1}(t, z=10)$ is the mean wind velocity at height $z$ for a reference point (\#1) within $(0,10)$ minutes; and $u(t, z)$ is the mean wind velocity at height $\mathrm{z}$ for point $(\# 1)$ within $(t, t+10)$ minutes.

Figure 7 shows the variance of the airflow field along a cross-section of the sand-control system. The combined effect of topography and the sand-control system increased the complexity of the wind velocities and their vertical distribution laws (Wiggs et al., 1996). There were obvious differences in the variations in wind velocity at heights of $0-60$ and $60-300 \mathrm{~cm}$. For the height of $60-300 \mathrm{~cm}$, the horizontal variations in the airflow field were consistent with topographic changes. Although horizontal variations in the airflow field for $0-60 \mathrm{~cm}$ were also affected by topographic changes, the horizontal wind velocities at greater heights may be less than those at lower heights.

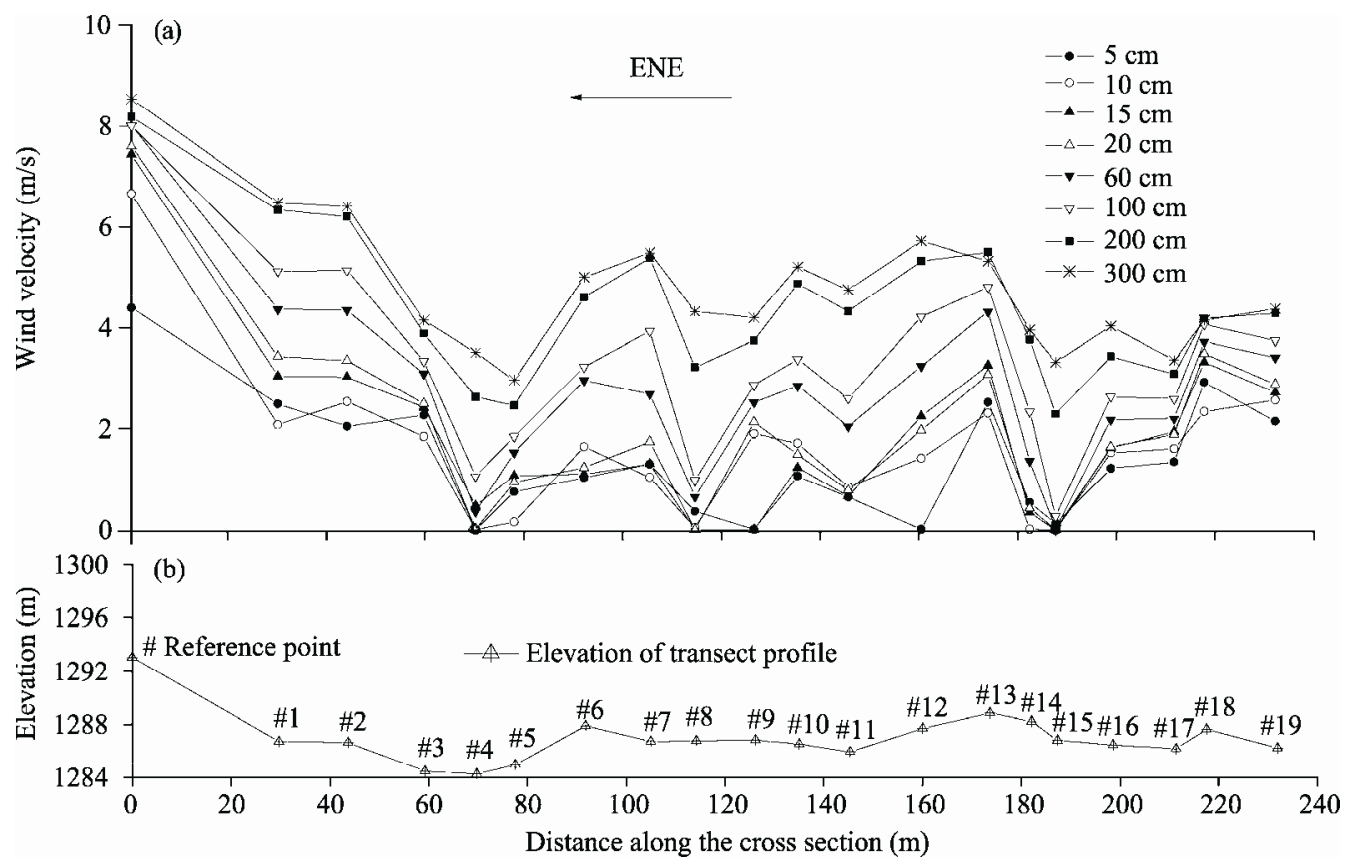

Fig. 7 Airflow field variations along the cross section of the sand-control system 
For points within the fences (\#1 and \#18), wind velocities at $10 \mathrm{~cm}$ were less than those at $5 \mathrm{~cm}$. For points within the straw checkerboards (\#2, \#4, \#13, $\# 16$ and \#17), the wind velocities at 5, 10, 15 and 20 $\mathrm{cm}$ followed a logarithmic pattern. For points within the protective belt (\#3, \#5-12 and \#14-15), the wind velocities at $5,10,15$ and $20 \mathrm{~cm}$ were affected by vegetation characteristics (Wolfe and Nickling, 1993) and no consistent results were observed.

Table 2 presents the ratios of wind velocities at different observation points to those of the reference point. The ratios were $0.00-0.57,0.00-0.39,0.00$ $0.45,0.00-0.46,0.00-0.54,0.03-0.64,0.28-0.78$ and $0.35-0.76$ for the heights of $5,10,15,20,60,100,200$ and $300 \mathrm{~cm}$, respectively. Above the mean height of the protection belt $(113 \mathrm{~cm})$, the wind velocity at 300 $\mathrm{cm}$ outside the sand-control system was $8.53 \mathrm{~m} / \mathrm{s}$; whereas the wind velocities at the corresponding height for \#1-19 ranged from 2.99 to $6.48 \mathrm{~m} / \mathrm{s}$. Within the height of the protection belt, the wind velocity at $100 \mathrm{~cm}$ outside the sand-control system was $8.00 \mathrm{~m} / \mathrm{s}$, whereas the wind velocities at the corresponding height for \#1-19 ranged from 0.27 to $5.12 \mathrm{~m} / \mathrm{s}$. Because the fences and the straw checkerboards had been fully or partially destroyed, geomorphology was the main impact factor for the decreased wind velocities. For example, point \#4 was located in a low-lying area, and its wind velocity ratios were $0.00,0.00,0.06,0.00$, $0.04,0.13,0.32$ and 0.41 for the heights of $5,10,15$, 20, 60, 100, 200 and $300 \mathrm{~cm}$, respectively. The height of vegetation was also an important parameter. Relative to the reference point, the aerodynamic roughness length increased within the protection belt (Lettau, 1969; Wiggs et al., 1996). The protective belt absorbed and scattered part of the momentum of the airflow. This disruption caused wind velocities to quickly decrease under the height of the vegetation after the airflow passed through the protective belt. The ratios of wind velocities within the protective belt were $0.00-0.52,0.00-0.28,0.00-0.33,0.00-0.33$, $0.00-0.40,0.03-0.53,0.28-0.66$ and $0.39-0.67$ for the heights of $5,10,15,20,60,100,200$ and $300 \mathrm{~cm}$, respectively. In addition, wind velocities changed significantly at different heights at points $\# 8$ and $\# 9$, located near the edge of the highway. The ratios of their wind speeds were $0.00-0.08,0.01-0.29,0.00-0.00$,
$0.00-0.28, \quad 0.08-0.31, \quad 0.12-0.36, \quad 0.39-0.46$ and $0.49-0.51$ for the heights of $5,10,15,20,60,100,200$ and $300 \mathrm{~cm}$, respectively; the corresponding mean wind velocity ratios were $0.04,0.15,0.00,0.14,0.20$, $0.24,0.43$ and $0.50 \mathrm{~m} / \mathrm{s}$. These results suggest that the sand-control system had a strong protective effect with regard to windblown sand (Coceal and Belcher, 2004; Dupont and Brunet, 2009).

Table 2 The ratios of wind velocities for different observation points relative to those of the corresponding heights at the reference point

\begin{tabular}{ccccccccc}
\hline \multirow{2}{*}{$\begin{array}{c}\text { Observa- } \\
\text { tion point }\end{array}$} & \multicolumn{7}{c}{ Ratio of wind velocities } \\
\cline { 2 - 10 } & $5 \mathrm{~cm}$ & $10 \mathrm{~cm}$ & $15 \mathrm{~cm}$ & $20 \mathrm{~cm}$ & $60 \mathrm{~cm}$ & $100 \mathrm{~cm}$ & $200 \mathrm{~cm}$ & $300 \mathrm{~cm}$ \\
\hline$\# 1$ & 0.57 & 0.31 & 0.41 & 0.45 & 0.54 & 0.64 & 0.78 & 0.76 \\
$\# 2$ & 0.47 & 0.38 & 0.41 & 0.44 & 0.54 & 0.64 & 0.76 & 0.75 \\
$\# 3$ & 0.52 & 0.28 & 0.33 & 0.33 & 0.39 & 0.42 & 0.48 & 0.49 \\
$\# 4$ & 0.00 & 0.00 & 0.06 & 0.00 & 0.04 & 0.13 & 0.32 & 0.41 \\
$\# 5$ & 0.17 & 0.02 & 0.14 & 0.13 & 0.19 & 0.23 & 0.30 & 0.35 \\
$\# 6$ & 0.24 & 0.25 & 0.15 & 0.16 & 0.37 & 0.40 & 0.56 & 0.59 \\
$\# 7$ & 0.30 & 0.16 & 0.18 & 0.23 & 0.34 & 0.49 & 0.66 & 0.64 \\
$\# 8$ & 0.08 & 0.01 & 0.00 & 0.00 & 0.08 & 0.12 & 0.39 & 0.51 \\
$\# 9$ & 0.00 & 0.29 & 0.00 & 0.28 & 0.31 & 0.36 & 0.46 & 0.49 \\
$\# 10$ & 0.24 & 0.26 & 0.17 & 0.20 & 0.36 & 0.42 & 0.60 & 0.61 \\
$\# 11$ & 0.15 & 0.13 & 0.09 & 0.10 & 0.26 & 0.33 & 0.53 & 0.56 \\
$\# 12$ & 0.00 & 0.21 & 0.30 & 0.26 & 0.40 & 0.53 & 0.65 & 0.67 \\
$\# 13$ & 0.58 & 0.35 & 0.44 & 0.40 & 0.54 & 0.60 & 0.67 & 0.62 \\
$\# 14$ & 0.12 & 0.00 & 0.05 & 0.06 & 0.17 & 0.29 & 0.46 & 0.46 \\
$\# 15$ & 0.03 & 0.00 & 0.00 & 0.00 & 0.00 & 0.03 & 0.28 & 0.39 \\
$\# 16$ & 0.28 & 0.23 & 0.22 & 0.22 & 0.27 & 0.33 & 0.42 & 0.47 \\
$\# 17$ & 0.31 & 0.24 & 0.26 & 0.25 & 0.27 & 0.32 & 0.38 & 0.39 \\
$\# 18$ & 0.67 & 0.35 & 0.45 & 0.46 & 0.46 & 0.51 & 0.51 & 0.49 \\
$\# 19$ & 0.49 & 0.39 & 0.37 & 0.38 & 0.43 & 0.47 & 0.52 & 0.51 \\
\hline & & & & & & & &
\end{tabular}

\subsection{Structural characteristics of the aeolian sand flow}

Figure 8 shows the vertical distribution of the aeolian sand flux as a function of height for 17 observation points (no data for points $\# 5$ and \#6). Except for points \#3, \#7, \#11, \#15 and \#16, the flux of aeolian sand decreased rapidly as height increased, consistent with prior results (Williams, 1964; Nalpanis, 1985; Anderson and Haff, 1988; Werner, 1990; Greeley et al., 1996; Cheng et al., 2007). The best regression results were obtained with a powder function by the TableCurve software. For \#3, \#7, \#11, \#15 and \#16, 
the vertical distribution of aeolian sand flux as a function of height is disordered because the points were located on the leeward side of a large slope, creating eddies in the airflow.

Table 3 shows the aeolian sand flux at the heights of $0-20,20-40$ and $40-60 \mathrm{~cm}$ for 17 observation points. Due to the effect of the sand-control system and topography on the aeolian sand flow, the ratios of 12 points for $20-60 \mathrm{~cm}$ exceeded $20 \%$, but the highest values were primarily located in the $0-20 \mathrm{~cm}$ range, indicating that blown sand motion occurred near the sand surface. These results were consistent with those in the literature for mobile sand surfaces (Bagnold, 1941; Chepil, 1963; Williams, 1964; Lammel et al., 2012; Pahtz et al., 2014). Because of the effects of the sand-control system, the ratios at $0-20 \mathrm{~cm}$ for the upwind points were larger than those for the leeward points, with a mean upwind value of 0.67 and a mean leeward value of 0.54 . The ratios for
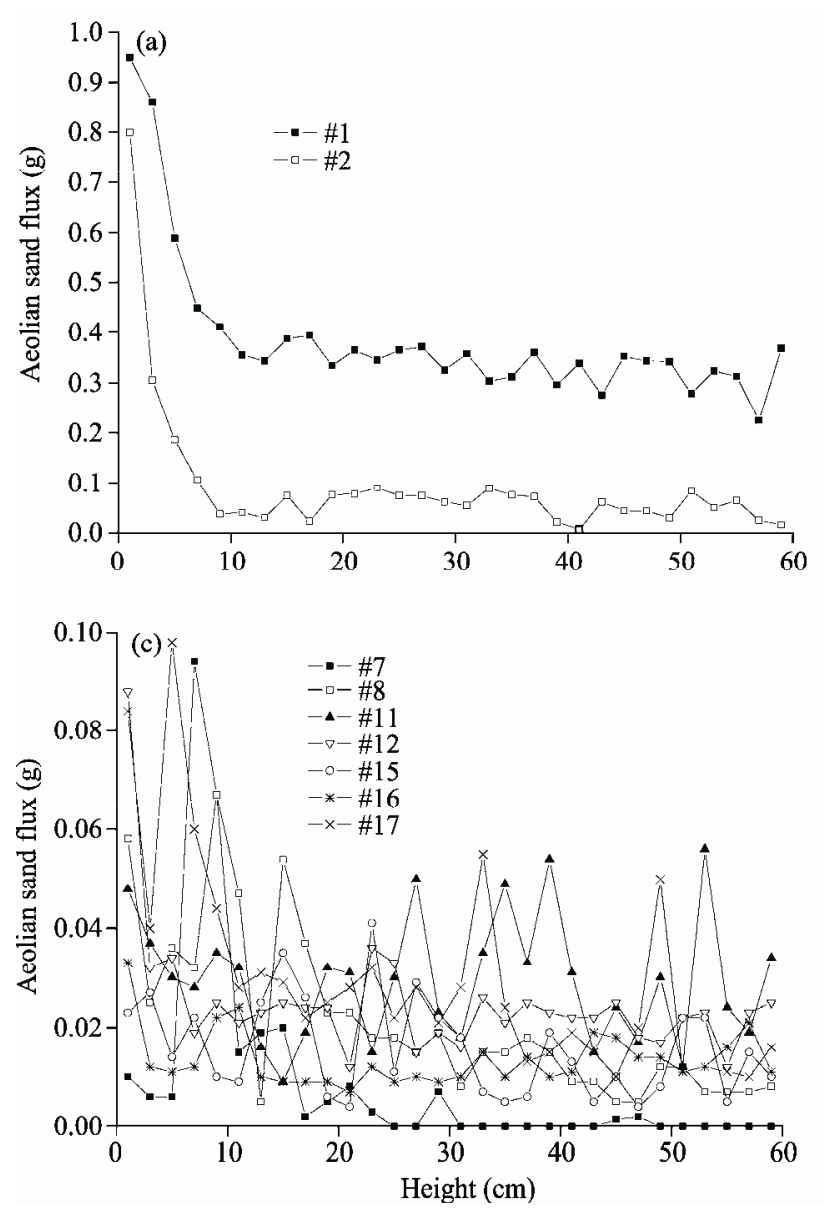

points \#3 and \#7 in the upwind protective belt at $0-20 \mathrm{~cm}$ were 0.81 and 0.92 , respectively, whereas the ratios for points $\# 10, \# 11, \# 12, \# 14$ and $\# 15$ in the leeward protective belt were $0.43,0.29,0.42$, 0.51 and 0.43 , respectively. In addition, topography was an important factor affecting the vertical structure of the aeolian sand flow.

The horizontal characteristics of aeolian sand flux were a key factor in assessing the efficiency of the sand-control system. However, no synchronous data on aeolian sand flux was taken; therefore, we discussed the horizontal characteristics of aeolian sand flux by using the decreased percentage between the observation points (\#1-19) and the reference point. As a whole, the decreased percentage ranged from $68.79 \%$ to $100 \%$. In detail, for observation points \#1 and \#18 within the fences, the decreased percentages were $85.66 \%$ and $68.79 \%$, respectively. For observation points $\# 2, \# 4, \# 13, \# 16$ and \#17 within the straw
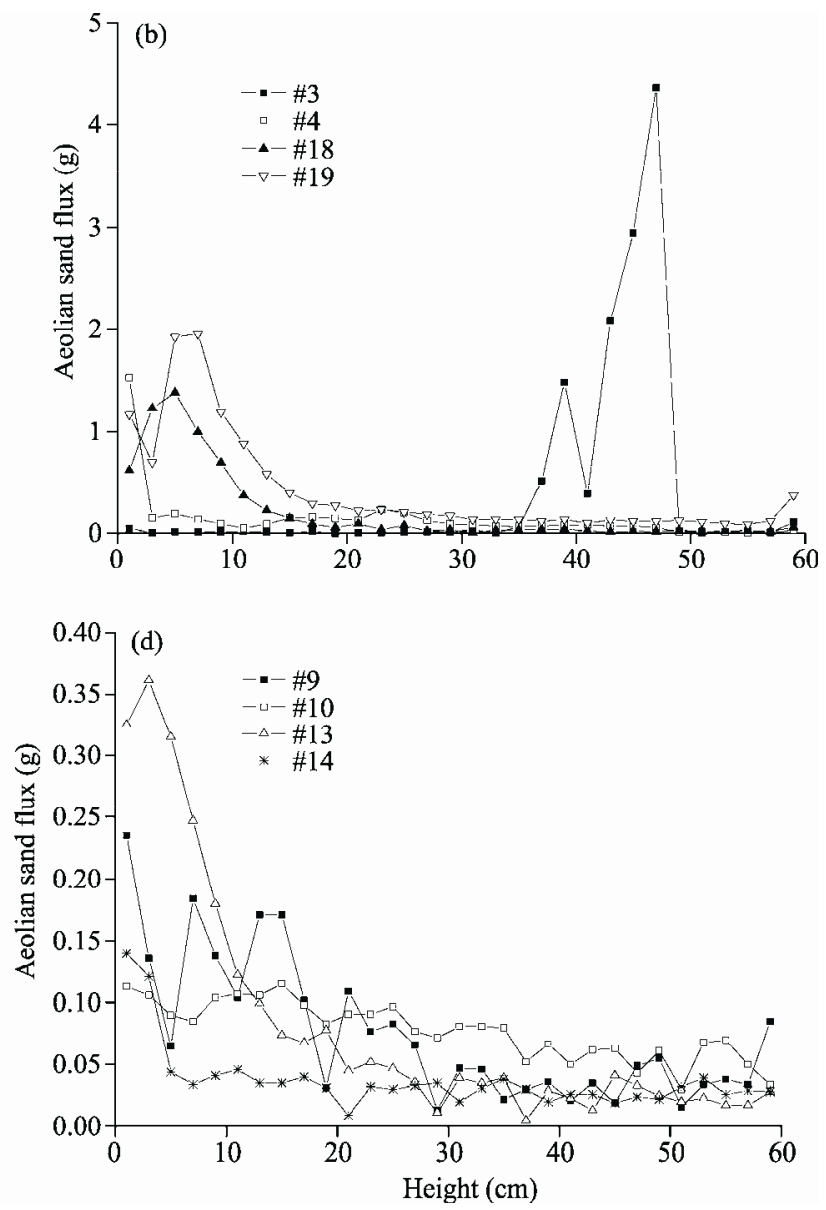

Fig. 8 Vertical distribution of aeolian sand flux for different observation points 
Table 3 The fluxes and rates of aeolian sand flow for the upper, middle, and lower layers of different observation points

\begin{tabular}{|c|c|c|c|c|c|c|c|}
\hline \multirow[b]{2}{*}{ Observation point } & \multicolumn{4}{|c|}{ Flux of different height layers $\left(\mathrm{g} /\left(\min \cdot\left(4 \mathrm{~cm}^{2}\right)\right)\right)$} & \multicolumn{3}{|c|}{ Proportion to the total flux } \\
\hline & $0-20 \mathrm{~cm}$ & $20-40 \mathrm{~cm}$ & $40-60 \mathrm{~cm}$ & $0-60 \mathrm{~cm}$ & $\mathrm{Q}_{0-20} / \mathrm{Q}_{0-60}$ & $\mathrm{Q}_{20-40} / \mathrm{Q}_{0-60}$ & $\mathrm{Q}_{40-60} / \mathrm{Q}_{0-60}$ \\
\hline$\# 1$ & 5.07 & 3.40 & 3.16 & 11.63 & 0.44 & 0.29 & 0.27 \\
\hline$\# 2$ & 1.68 & 0.69 & 0.42 & 2.79 & 0.60 & 0.25 & 0.15 \\
\hline \#3 & 9.94 & 2.14 & 0.14 & 12.22 & 0.81 & 0.18 & 0.01 \\
\hline$\# 4$ & 2.66 & 1.13 & 0.34 & 4.13 & 0.64 & 0.27 & 0.08 \\
\hline$\# 5$ & - & - & - & - & - & - & - \\
\hline$\# 6$ & - & - & - & - & - & - & - \\
\hline$\# 7$ & 0.24 & 0.02 & 0.00 & 0.26 & 0.92 & 0.08 & 0.00 \\
\hline$\# 8$ & 0.38 & 0.16 & 0.08 & 0.62 & 0.61 & 0.26 & 0.13 \\
\hline$\# 9$ & 1.34 & 0.53 & 0.39 & 2.26 & 0.59 & 0.23 & 0.17 \\
\hline$\# 10$ & 1.00 & 0.79 & 0.53 & 2.32 & 0.43 & 0.34 & 0.23 \\
\hline$\# 11$ & 0.26 & 0.34 & 0.29 & 0.89 & 0.29 & 0.38 & 0.33 \\
\hline$\# 12$ & 0.32 & 0.23 & 0.21 & 0.76 & 0.42 & 0.30 & 0.28 \\
\hline \#13 & 1.87 & 0.34 & 0.24 & 2.45 & 0.76 & 0.14 & 0.10 \\
\hline$\# 14$ & 0.57 & 0.28 & 0.27 & 1.12 & 0.51 & 0.25 & 0.24 \\
\hline$\# 15$ & 0.20 & 0.16 & 0.11 & 0.47 & 0.43 & 0.34 & 0.23 \\
\hline$\# 16$ & 0.15 & 0.11 & 0.15 & 0.41 & 0.37 & 0.27 & 0.37 \\
\hline$\# 17$ & 0.46 & 0.27 & 0.17 & 0.90 & 0.51 & 0.30 & 0.19 \\
\hline$\# 18$ & 5.79 & 0.38 & 0.23 & 6.40 & 0.90 & 0.06 & 0.04 \\
\hline$\# 19$ & 9.34 & 1.66 & 1.35 & 12.35 & 0.76 & 0.13 & 0.11 \\
\hline
\end{tabular}

checkerboards, the decreased percentages were 94.76\%-99.37\%. For observation points \#3, \#5-12 and \#14-15 within the protective belt, the decreased percentage was $77.93 \%-100 \%$. For point \#19 outside the system, the decreased percentage was $80.93 \%$. Therefore, although the straw checkerboards were largely destroyed, the protection belt has replaced it, creating protective effect from windblown sand.

\subsection{Characteristics of surface erosion and deposi- tion}

In this paper, the total amount of erosion and deposition was defined as the accumulation of erosion and deposition, respectively. The total thicknesses of erosion and deposition for these points ranged from 0.3 to $14.6 \mathrm{~cm}$, but many surprising erosion and deposition thicknesses were found. Deposition thicknesses ranged from 1.9 to $100.8 \mathrm{~cm}$, and erosion thicknesses ranged from 3.5 to $100.4 \mathrm{~cm}$ (Fig. 9). The erosion and deposition differences between points within and outside the prevention and control system were significant (Fig. 9). For points \#1, \#2 and \#3, which were outside the system, the windward slope toe (\#1) and middle part (\#2) of the sand dune mainly exhibited surface deposition, whereas the crest primarily experienced surface erosion. These results were consistent with previous research (Wang and Lei, 1998). Furthermore, the thicknesses of deposition for points $\# 1, \# 2$ and \#3 were 9.6, 9.8 and $11.6 \mathrm{~cm}$, respectively, and their thicknesses of erosion were 7.2, 9.5 and 22.1 $\mathrm{cm}$, respectively. This illustrated that an equilibrating process of erosion and deposition on the windward slopes was determined by the airflow near the surface and the shapes of the sand dunes. For points \#6, \#8-11 and \#13 within the protective belt, surface deposition was the main process. Their deposition thicknesses were $15.1,11.1,7.4,7.4,3.6$ and $16.5 \mathrm{~cm}$, whereas their corresponding erosion thicknesses were only 8.9, 8.0, $4.8,2.9,2.3$ and $1.9 \mathrm{~cm}$, respectively. The depositional differences for the different points were influenced by vegetation characteristics (such as height, crown and shape), the layouts of the protective belt and the landforms. For monitoring points within the fences and the straw checkerboards, both of which had been mostly destroyed, the erosional and depositional processes were similar to those of the mobile sand surface. As a whole, their thicknesses of erosion and 


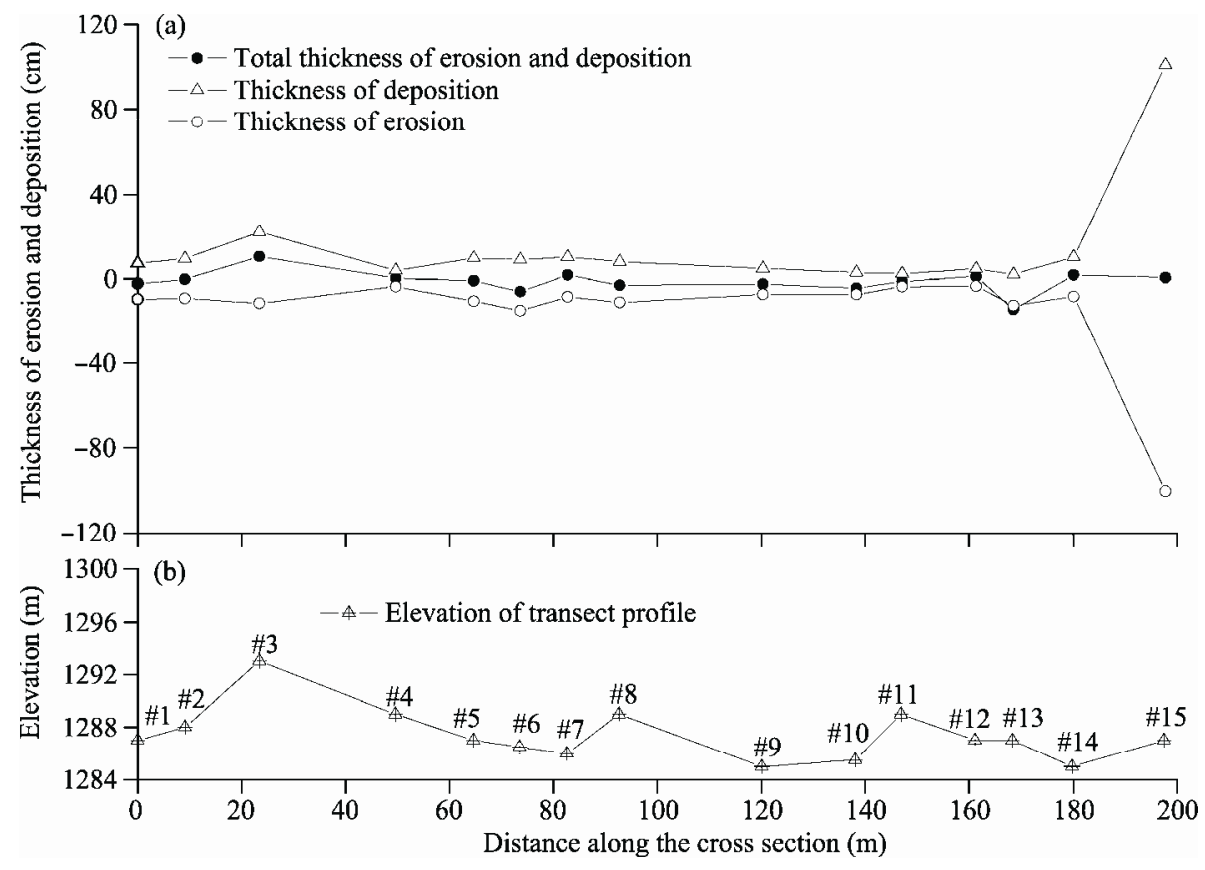

Fig. 9 The total amount of erosion and deposition during the monitoring period from 24 March 2010 to 21 February 2011

deposition were less than those within the protective belt because of the effect of geomorphology.

Because of the large differences in monthly erosion and deposition thicknesses between point \#15 and the other 14 monitoring points, this paper provides the monthly values from 3 April 2010 to 31 December 2010 (Fig. 10). As a whole, the monthly erosion and deposition thicknesses were consistent with the frequency of wind velocities greater than $5 \mathrm{~m} / \mathrm{s}$ at the Minfeng meteorological station (Fig. 3). For example, there were large erosion and deposition thicknesses for high frequency of wind velocities during the period from April 2010 to August 2010, whereas relatively small erosion and deposition thicknesses were observed between September 2010 and November 2010 because of low frequency of wind velocities.

Figure 11 provides the total amount of erosion and deposition for 15 different monitoring points for two six-month periods (14 April 2009-14 October 2009 and 14 April 2010-14 October 2010). Although there were large differences in the scale of the total amount of erosion and deposition for several monitoring points (\#2, $\# 5$, \#6 and \#15) between the two years, the trends of change were very consistent. As a whole, for monitoring points \#6, \#8-11 and \#13 within the protective belt, deposition was the main process and the change trends were very consistent (except for \#6) because of the effect of geomorphology. Similarly, geomorphology determined the amount of erosion and deposition for those monitoring points within the fences and straw checkerboards and outside the sand-control system. This indicates that geomorphology plays an important role in the prevention and control of sand movement.
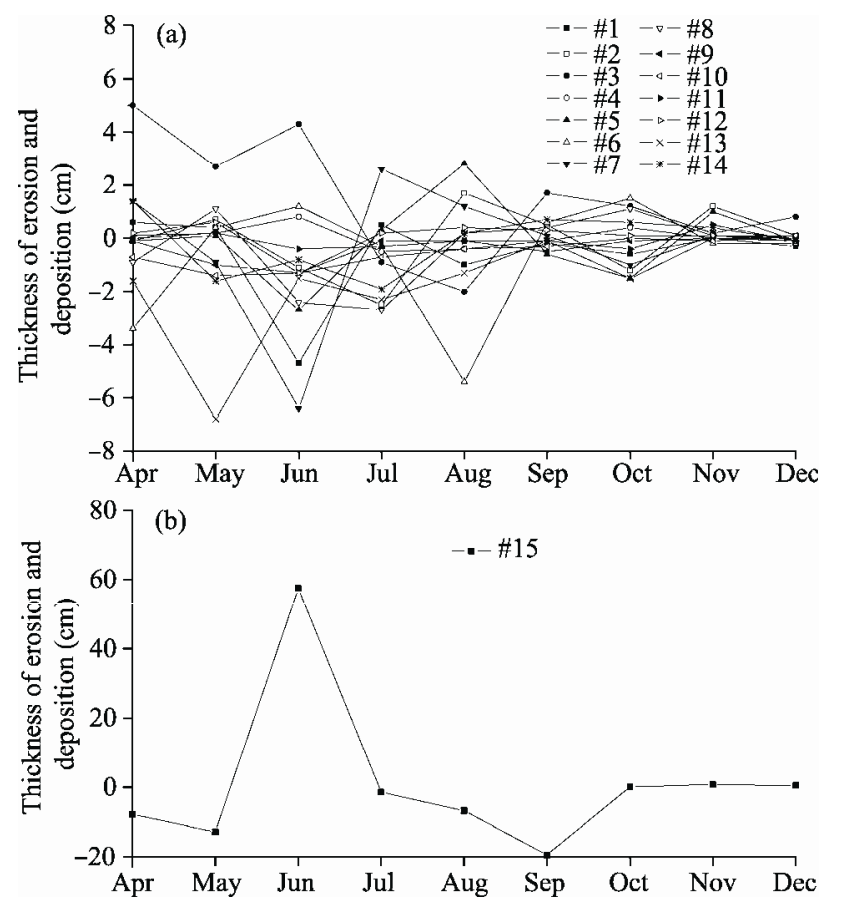

Fig. 10 Monthly erosion and deposition thickness for 15 monitoring points in 2010 


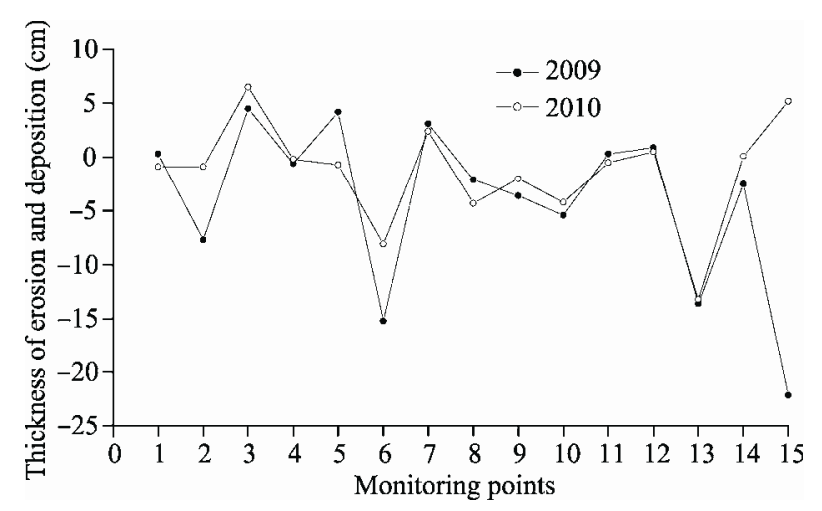

Fig. 11 The total amount of erosion and deposition of sand at 15 different monitoring points for two six-month periods (14 April 2009-14 October 2009 and 14 April 2010-14 October 2010)

\subsection{Size characteristics of surface sand grains}

Except for point \#3 that was located at the crest of the sand dune, the grain sizes of most points were fine to very fine (Table 4), which is consistent with previous research (Chen and Lei, 1992; Chen, 1993; He et al., 2012). The percentages of fine and very fine sand contents ranged from $30.83 \%$ to $90.85 \%$. The mean value of fine and very fine sand content outside the system (\#1, \#2 and \#3) was $56.63 \%$, whereas the mean value within the system was $76.37 \%$. Furthermore, no medium or coarse sand was found within the protective belt, whereas coarse and very coarse sand composes $14.67 \%-66.13 \%$ of the sand grains outside the system, and $22.61 \%-30.96 \%$ within the fences and
$0-32.56 \%$ within the straw checkerboards. In addition, the mean diameters of sand grains were similar to the mechanical compositions. For example, the diameters of sand grains outside the system ranged from 1.09 to $2.94 \varphi$, with a mean value of $1.93 \varphi$, whereas the diameters of sand grains within the protective belt ranged from 3.18 to $3.64 \varphi$, with a mean value of $3.37 \varphi$. Furthermore, the diameters of sand grains within the straw checkerboards ranged from 2.25 to $3.32 \varphi$, with a mean value of $2.94 \varphi$, and the diameters of sand grains within the fences ranged from 1.64 to $3.31 \varphi$, with a mean value of $2.18 \varphi$. Changes in the mean diameters at different points were also shown in the standard deviations of the diameters. This observation indicates that the protective belt greatly prevented and controlled the blown sand flow on the highway.

The mechanical composition and diameter parameters of the sand grains were significantly influenced by local wind speeds. The design of the sand-control system caused coarse sand to be deposited upwind outside the system and fine sand to be deposited inside the system. Morphology changes also influenced the mechanical composition and diameters of sand grains. For example, points \#1-3 were located on a windward slope toe, mid-slope and the crest of a sand dune, respectively.

Table 4 Composition of sand grain sizes at the observation points

\begin{tabular}{|c|c|c|c|c|c|c|c|c|}
\hline \multirow{2}{*}{$\begin{array}{l}\text { Observation } \\
\text { point }\end{array}$} & \multicolumn{6}{|c|}{ Composition (\%) } & \multirow{2}{*}{$\begin{array}{c}\text { Mean diameter } \\
(\varphi)\end{array}$} & \multirow[b]{2}{*}{ Standard deviation } \\
\hline & $\begin{array}{c}\text { Silt } \\
(4-8 \varphi)\end{array}$ & $\begin{array}{c}\text { Very fine sand } \\
(3-4 \varphi)\end{array}$ & $\begin{array}{c}\text { Fine sand } \\
(2-3 \varphi)\end{array}$ & $\begin{array}{c}\text { Medium sand } \\
(1-2 \varphi)\end{array}$ & $\begin{array}{c}\text { Coarse sand } \\
(0-1 \varphi)\end{array}$ & $\begin{array}{l}\text { Very coarse sand } \\
(<0 \varphi)\end{array}$ & & \\
\hline$\# 1$ & 14.85 & 44.80 & 20.43 & 7.05 & 12.20 & 0.67 & 2.32 & 0.15 \\
\hline$\# 2$ & 11.51 & 48.88 & 24.94 & 6.52 & 7.94 & 0.21 & 2.94 & 0.11 \\
\hline$\# 3$ & 3.04 & 19.92 & 10.91 & 19.28 & 39.41 & 7.44 & 1.09 & 0.32 \\
\hline$\# 4$ & 16.62 & 37.57 & 14.86 & 3.42 & 19.36 & 8.18 & 1.64 & 0.32 \\
\hline$\# 5$ & 7.29 & 32.99 & 27.16 & 23.38 & 9.18 & 0.00 & 2.25 & 0.15 \\
\hline$\# 6$ & 13.35 & 58.41 & 28.25 & 0.00 & 0.00 & 0.00 & 3.32 & 0.04 \\
\hline$\# 7$ & 16.24 & 59.14 & 24.63 & 0.00 & 0.00 & 0.00 & 3.32 & 0.04 \\
\hline$\# 8$ & 15.79 & 59.79 & 24.43 & 0.00 & 0.00 & 0.00 & 3.32 & 0.04 \\
\hline$\# 9$ & 23.66 & 59.46 & 16.88 & 0.00 & 0.00 & 0.00 & 3.47 & 0.03 \\
\hline$\# 10$ & 17.67 & 58.38 & 23.95 & 0.00 & 0.00 & 0.00 & 3.32 & 0.04 \\
\hline$\# 11$ & 33.43 & 50.20 & 16.38 & 0.00 & 0.00 & 0.00 & 3.64 & 0.04 \\
\hline$\# 12$ & 22.98 & 53.55 & 19.06 & 2.21 & 2.20 & 0.00 & 3.32 & 0.05 \\
\hline$\# 13$ & 12.36 & 57.24 & 30.40 & 0.00 & 0.00 & 0.00 & 3.18 & 0.04 \\
\hline$\# 14$ & 8.98 & 57.26 & 33.59 & 0.17 & 0.00 & 0.00 & 3.18 & 0.04 \\
\hline$\# 15$ & 4.50 & 37.49 & 35.40 & 12.82 & 9.48 & 0.31 & 2.40 & 0.14 \\
\hline
\end{tabular}


Their mean content of silt-sized sand was $9.80 \%$, less than that within the system $(17.18 \%)$. The contents of silt-sized sand at points $\# 1-3$ were $14.85 \%, 11.51 \%$ and $3.04 \%$, respectively, whereas the contents of coarse sand were $12.87 \%, 8.15 \%$ and $46.85 \%$, respectively.

\section{Conclusions}

This paper focused on blown sand motion within the sand-control system for the classical section in the southern portion of the Taklimakan Desert Highway by the field observation data on airflow, aeolian sand transport, and erosional and depositional processes. The main results are as follows: (1) The existing sand-control system is highly effective at preventing and controlling blow sand motion. Wind velocities within sand-control system were approximately $33 \%-100 \%$ of those for the same heights above the mobile surface, the aeolian sand fluxes were approximately $0-31.21 \%$ of those on the mobile surface, and sand grains with a mean diameter of $2.89 \varphi$ were finer than those outside of the system $(2.15 \varphi)$. In addition, the wind velocities basically followed a logarithmic law, and the airflows along the classical section were mainly determined by topography and vegetation. (2) There were obvious erosion and deposition phenomena above the surface within the sand-control system, and they had very consistent change trends for all observation points in the two observation years. Although the total thicknesses of erosion and deposition were not great, the deposition and erosion thicknesses were large. The total thicknesses of erosion and deposition ranged from 0.30 to $14.6 \mathrm{~cm}$, with a mean value of $3.67 \mathrm{~cm}$. In contrast, the deposition thicknesses were $1.90-22.10 \mathrm{~cm}$, with a mean value of $7.59 \mathrm{~cm}$, and erosion thicknesses were $3.51-15.10 \mathrm{~cm}$, with a mean value of $8.75 \mathrm{~cm}$.

\section{Acknowledgements}

The study was supported by the National Natural Science Foundation of China $(41271020,41330746)$ and CERS-China Equipment and Education Resources System (CERS-1-109).

\section{References}

Anderson R S, Haff P K. 1988. Simulation of eolian saltation, Science, 241: 820-823.
Bagnold R A. 1941. The Physics of Blown Sand and Sand Dunes. New York: William Morrow and Company, Inc.

Chen W N, Lei J Q. 1992. Grain size features of sands in different localities of barchan dunes, Taklamakan Desert. Journal of Arid Land Resources and Environment, 6(2): 101-109. (in Chinese)

Chen W N. 1993. Grain size parameters of aeolian sediments in the vicinity of the longitude $84^{\circ} \mathrm{E}$. Acta Geographica Sinica, $48(1)$ : 33-46. (in Chinese)

Cheng H, Zou X Y, Zhang C L. 2007. A study of the number of sand grains lifting off per unit time and per unit sand bed area. Journal Geophysical Research: Atmospheres, doi: 10.1029/ 2006JD007641.

Chepil W S, Woodruff N P. 1963. The physics of wind erosion and its control. Advances in Agronomy, 15: 211-302.

Coceal O, Belcher S E. 2004. A canopy model for mean winds through urban areas. Quarterly Journal of the Royal Meteorogical Society, 130: 1349-1372.

Dong Z B, Chen G T, Han Z W, et al. 1997. Hazard of blown sand of Taklimakan Desert Highway. Chinese Journal of Environmental Science, 18(1): 4-9. (in Chinese)

Dupont S, Brunet Y. 2009. Coherent structures in canopy edge flow: a large-eddy simulation study. Journal of Fluid Mechanics. 630: 93-128.

Greeley R, Blumberg D G, Williams S H. 1996. Field measurement of the flux and speed of wind-blown sand. Sedimentology, 43: 41-52.

Han Z W, Chen W N, Chen G T, et al. 1993. The protective efficiency of the drifting-sand-dune control system along a test section of the Tarim Desert Highway. Journal of Desert Research, 13(4): 44-51. (in Chinese)

Han Z W, Chen G T, Hu Y T, et al. 2000. Discussion on problems about construction of sand-controlling systems along desert highway in Tarim Basin, Taklimakan Desert. Journal of Arid Land Resources and Environment, 14(2): 34-40. (in Chinese)

Han Z W, Dong Z B, Wang T, et al. 2003. Observation study of several characteristics of blown sand motion in Taklimakan Desert. Science in China (Series D), 33(3): 255-263. (in Chinese)

Han Z W, Wang T, Dong Z B, et al. 2005. Spatial-temporal distribution of blown sand activities along Taklimakan Desert Highway. Scientia Geographica Sinica, 25(4): 455-460. (in Chinese)

He J J, Quan Z J, Pan M H, et al. 2012. Characteristics of grain-size over four barchan dunes distributed downward engineering system of prevention and control of Taklimakan desert highway along wind direction in interdune corridor of ridges. Jouranl of Beijing Normal University (Natural Science), 48(3): 262-297. (in Chinese)

Jin C N, Dong Z B, Li J J, et al. 2005. Blown sand deposits and its indications on wind activities around high windbreaks. Journal of Desert Research, 25(5): 652-657. (in Chinese)

Jin C N, Li Z L, Dong Z B, et al. 2007. Study on problems in sand consolidation measures for the Taklimakan desert highway. Journal of Highway and Transportation Research and Development, 24(5): 1-6. (in Chinese)

Jin C N, Li S, Liu J, et al. 2008. Survey and analysis of hazard of blown sand of characteristics section of along desert highway in Tarim Basin. China Highway, 28(4): 20-24. (in Chinese)

Lammel M, Rings D, Kroy K. 2012. A two-species continuum model for aeolian sand transport. New Journal of Physics, doi: 
10.1088/1367-2630/14/9/093037.

Lei J Q, Wang X Q, Wang D, et al. 2002. The blown sand disaster to the Tarim Desert Highway in Xinjiang, China. Science in China (Series D), 45(Supp1.): 165-173. (in Chinese)

Lei J Q, Li S Y, Fan D D, et al. 2008a. Classification and division into districts of harm of blown sand along desert highway in Tarim Basin. Chinese Science Bulletin, 53(Suppl.): 1-6. (in Chinese)

Lei J Q, Li S Y, Jin Z Z, et al. 2008b. Synthetic ecological environment effect of engineering of protective belts along desert highway in Tarim Basin. Chinese Science Bulletin, 53(Supp1.): 169-178. (in Chinese)

Lettau H.1969. Notes on the aerodynamic roughness parameter estimation on the basis of roughness element description. Journal of Applied Meteorology, 8: 828-830.

Li B S, Dong G, Ding T H, et al. 1990. Several arguments for the Aeolian geomorphology in the eastern Taklimakan Desert. Chinese Science Bulletin, 35(23): 1815-1818. (in Chinese)

Li S Y, Lei J Q, Xu X W, et al. 2006. Morphological changes of surface under the effect of Tarim desert highway. Chinese Science Bulletin, 51: 81-87. (in Chinese)

Liu G Q. 2009. Atlas Map of Xinjiang Uygur Autonomous Region. Beijing: SinoMaps Press, 228-229. (in Chinese)

Nalpanis P. 1985. Saltating and suspended particles over flat and sloping surface. II. Experiments and numerical simulations. In: Proceedings of international workshop on the physics of blown sand. Denmark: Aarhus University, 37-66.

Pahtz T, Parteli E J R, Kok J F.et al. 2014. Analytical model for flux saturation in sediment transport. Physical Review E, 89, 052213.

Qu J J, Lin Y Q, Zu R P, et al. 2005. Study on comprehensive sand-protecting efficiency of semi-buried checkerboard sand- barriers. Journal of Desert Research, 25(3): 329-335. (in Chinese)
Wang X Q, Lei J Q. 1998. Sand deposit and erosion characteristics of semi-fixed linear dunes in Gurbantunggut Gesert. Arid Zone Research, 15(3): 35-39. (in Chinese)

Wang X M, Dong Z B, Zhang J W, et al. 2002a. Geomorphology of sand dunes in the northeast Taklimakan Sand Sea. Geomorphology, 42: $183-195$.

Wang X M, Dong Z B, Zhang J W, et al. 2002b. Relations between morphology, airflow, sand flux and particle size on transverse dunes, Taklimakan Sand Sea. Earth Surface Processes and Landforms, 27: 515-526.

Werner B T. 1990. A steady-state model of wind-blown sand transport. Journal of Geology, 1: 1-17.

Wiggs G F S, Livingstone I, Thomas D S G, et al. 1996. Airflow and roughness characteristics over partially vegetated linear dunes in the southwest Kalahari desert. Earth Surface Processes and Landforms, 21: 19-34.

Williams G.1964. Some aspects of the Aeolian saltation load. Sedimentology, 3: 257-287.

Wolfe S A, Nickling W G. 1993. The protective role of sparse vegetation in wind erosion. Progress in Physical Geography, 17: 50-68.

Wu Z. 1981. Approach to the genesis of the Taklimakan Desert. Acta Geographica Sinica, 36(3): 280-291. (in Chinese)

Xia X C, Chen G T, Li C S, et al. 1995. Study on the engineering techniques of oil-transporting highway in Tarim Desert. Journal of Desert Research, 15(1): 1-9. (in Chinese)

Zhang J W, Chen G T, Chen F H, et al. 1999. Dynamic processes of linear dunes in central Taklimakan Desert. Journal of Desert Research, 19(2): 128-134. (in Chinese)

Zhu Z D, Chen Z P, Wu Z. 1981. Study on the Geomorphology of Wind-drift Sands in the Taklimakan Desert. Beijing: Science Press: 27-55. (in Chinese) 